\title{
Ventilation/carbon dioxide output relationships during exercise in health
}

\author{
Susan A. Ward
}

\section{Number 4 in the Series "Ventilatory efficiency and its clinical prognostic value in cardiorespiratory disorders" Edited by Pierantonio Laveneziana and Paolo Palange}

Human Bio-Energetics Research Centre, Crickhowell, Powys, UK.

Corresponding author: Susan A. Ward (saward@dsl.pipex.com)

Shareable abstract (@ERSpublications)

The efficiency of $\mathrm{CO}_{2}$ clearance at the lungs in exercise is estimated from the relationship between ventilation and $\mathrm{CO}_{2}$ elimination rate. It is compromised in lung and cardiovascular disease, stressing breathing and shortness of breath, and therefore impairing exercise capacity. https://bit. ly/3gYY866

Cite this article as: Ward SA. Ventilation/carbon dioxide output relationships during exercise in health. Eur Respir Rev 2021; 30: 200160 [DOI: 10.1183/16000617.0160-2020].

Copyright @ERS 2021

This article is open access and distributed under the terms of the Creative Commons Attribution Non-Commercial Licence 4.0.

Received: 26 May 2020 Accepted: 22 Aug 2020

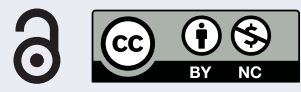

\section{Abstract}

"Ventilatory efficiency" is widely used in cardiopulmonary exercise testing to make inferences regarding the normality (or otherwise) of the arterial $\mathrm{CO}_{2}$ tension $\left(P_{\mathrm{aCO}_{2}}\right)$ and physiological dead-space fraction of the breath $\left(V_{\mathrm{D}} / V_{\mathrm{T}}\right)$ responses to rapid-incremental (or ramp) exercise. It is quantified as: 1 ) the slope of the linear region of the relationship between ventilation $\left(V_{\mathrm{E}}^{\prime}\right)$ and pulmonary $\mathrm{CO}_{2}$ output $\left(V^{\prime} \mathrm{CO}_{2}\right)$; and/or 2) the ventilatory equivalent for $\mathrm{CO}_{2}$ at the lactate threshold $\left(V_{\mathrm{E}}^{\prime} / V_{\mathrm{CO}_{2}}^{\prime} \mathrm{LT}\right)$ or its minimum value $\left(V_{\mathrm{E}}^{\prime} / V^{\prime} \mathrm{CO}_{2} \mathrm{~min}\right)$, which occurs soon after $\mathrm{LT}$ but before respiratory compensation. Although these indices are normally numerically similar, they are not equally robust. That is, high values for $V_{\mathrm{E}}^{\prime} / V_{\mathrm{CO}_{2}}^{\prime} \hat{\mathrm{LT}}$ and $V_{\mathrm{E}}^{\prime} / V^{\prime} \mathrm{CO}_{2}$ min provide a rigorous index of an elevated $V_{\mathrm{D}} / V_{\mathrm{T}}$ when $P_{\mathrm{aCO}}$ is known (or can be assumed) to be regulated. In contrast, a high $V_{\mathrm{E}}^{\prime}-V^{\prime} \mathrm{CO}_{2}$ slope on its own does not, as account has also to be taken of the associated normally positive and small $V_{\mathrm{E}}^{\prime}$ intercept. Interpretation is complicated by factors such as: the extent to which $P_{\mathrm{aCO}}$ is actually regulated during rapid-incremental exercise (as is the case for steady-state moderate exercise); and whether $V^{\prime}{ }_{E} / V^{\prime} \mathrm{CO}_{2} \hat{\mathrm{LT}}$ or $V^{\prime}{ }_{\mathrm{E}} / V^{\prime} \mathrm{CO}_{2}$ min provide accurate reflections of the true asymptotic value of $V_{\mathrm{E}}^{\prime} / V^{\prime} \mathrm{CO}_{2}$, to which the $V_{\mathrm{E}}^{\prime}-V^{\prime} \mathrm{CO}_{2}$ slope approximates at very high work rates.

\section{Introduction}

"Ventilatory efficiency", the ventilation $\left(V_{\mathrm{E}}^{\prime}\right)$ associated with eliminating a given level of metabolically produced $\mathrm{CO}_{2}$ as pulmonary $\mathrm{CO}_{2}$ output $\left(V_{\mathrm{CO}_{2}}^{\prime}\right)$, is a construct that has evolved from the discipline of cardiopulmonary exercise testing (CPET), whereby the integrated system function of muscle metabolism, the circulation and heart, pulmonary gas exchange and ventilation are interrogated and monitored in real time (typically breath-by-breath) by means of a rapid-incremental or ramp exercise test [1-3]. Fundamental to any mechanistic consideration of ventilatory efficiency is that $V^{\prime}{ }_{\mathrm{E}}$ during moderate exercise (i.e. below the lactate threshold, (LT; i.e. estimated, rather than directly measured), with work rates not eliciting a sustained metabolic acidosis) operates as if it is coupled to the requirement for clearing the associated endogenous $\mathrm{CO}_{2}$ load accruing from aerobic metabolism, to regulate arterial $\mathrm{CO}_{2}$ tension $\left(P_{\mathrm{aCO}}\right)$ at or close to its resting value (reviewed in [4-8]). Exactly how this apparently $\mathrm{CO}_{2}$-linked control is mediated remains tantalisingly elusive, however, not the least because of the absence of a significant sustained $P_{\mathrm{aCO}}$ error signal that could stimulate the carotid body and central chemoreflexes (reviewed in [6-8]). It had been suggested that $V_{\mathrm{E}}^{\prime}$ is driven, largely if not entirely, by the " $\mathrm{CO}_{2}$ flow to the lungs", i.e. the product of venous return and the mixed-venous $\mathrm{CO}_{2}$ content [9]. Subsequently, a logical imprecision in this reasoning was identified by Whipp [10]: "Such proposals, however, fail to meet the $P_{\mathrm{aCO}_{2}}$-regulatory demands of the control. That is, any such control link will depend not on the rate at which $\mathrm{CO}_{2}$ is brought to the lung per 
unit time but that minus the rate at which $\mathrm{CO}_{2}$ leaves the lung in the pulmonary arterial blood". The precise substrate of such a $\mathrm{CO}_{2}$-linked mechanism has, to date, remained obscure.

It is important to recognise that $P_{\mathrm{aCO}}$ regulation during moderate exercise is expressed through the transform not only of the proportional matching of $V_{\mathrm{E}}^{\prime}$ to $V^{\prime} \mathrm{CO}_{2}$ but also of the physiological dead space fraction of the breath $\left(V_{\mathrm{D}} / V_{\mathrm{T}}\right)[7,8,10]$ :

$$
P_{\mathrm{aCO}_{2}}=863 /\left(\left(V_{\mathrm{E}}^{\prime} / V_{\mathrm{CO}_{2}}^{\prime}\right) \cdot\left(1-V_{\mathrm{D}} / V_{\mathrm{T}}\right)\right)
$$

where 863 is the constant that corrects for the different conditions of reporting gas volumes (standard temperature and pressure, dry; body temperature and pressure, saturated) and transformation of fractional concentration to partial pressure; and $V^{\prime}{ }_{\mathrm{E}} / V^{\prime} \mathrm{CO}_{2}$ is the ventilatory equivalent for $\mathrm{CO}_{2}$.

At higher work rates engendering a metabolic (largely lactic) acidosis, $V_{\mathrm{E}}^{\prime}$ has the further imperatives of a) clearing the additional $\mathrm{CO}_{2}$ resulting from bicarbonate-buffering of the metabolic acidosis and b) generating respiratory compensation to constrain the falling arterial $\mathrm{pH}\left(\mathrm{pH}_{\mathrm{a}}\right)[5,7,8,11-14]$. This can usefully be expressed through a modification of the Henderson-Hasselbalch equation (i.e. $\mathrm{pH}=\mathrm{pK}+\log$ $\left[\mathrm{HCO}_{3}^{-}\right] / \alpha \cdot P_{\mathrm{aCO}_{2}}$ ) by substituting for $P_{\mathrm{aCO}_{2}}$ from equation 1:

$$
\mathrm{pH}_{\mathrm{a}}=\mathrm{pK}^{\prime}+\underbrace{\left(\log \left(\left[\mathrm{HCO}_{3}^{-}\right]_{\mathrm{a}} / 25.9\right)\right)} \cdot \underbrace{\left(V_{\mathrm{E}}^{\prime} / V_{\mathrm{CO}_{2}}^{\prime}\right)} \cdot \underbrace{\left(1-V_{\mathrm{D}} / V_{\mathrm{T}}\right)}
$$

where $\mathrm{pK}^{\prime}$ is the negative logarithm of the carbonic acid ionisation constant; $\left[\mathrm{HCO}_{3}^{-}\right]_{\mathrm{a}}$ is arterial bicarbonate concentration; and $\alpha$ is the $\mathrm{CO}_{2}$ solubility coefficient $\left.\left(0.03 \mathrm{mmol} \cdot \mathrm{mmHg}^{-1}\right)\right)$. The bracketed terms represent (from left to right): metabolic acid-base "set-point”, "ventilatory control” and pulmonary gas-exchange "efficiency" operators [8]. Thus, the effectiveness of respiratory compensation depends not only on $V_{\mathrm{E}}^{\prime} / V^{\prime} \mathrm{CO}_{2}$ increasing absolutely, but also relative to $V_{\mathrm{D}} / V_{\mathrm{T}}$.

\section{The $V^{\prime}{ }^{-}-V^{\prime}{ }_{\mathrm{CO}}$, relationship}

The significance of $P_{\mathrm{aCO}}$ and $V_{\mathrm{D}} / V_{\mathrm{T}}$ in setting the $V_{\mathrm{E}}^{\prime}$ requirements during exercise is illustrated by re-arranging equation 1 in terms of $V^{\prime}{ }_{E}$ :

$$
V_{\mathrm{E}}^{\prime}=863 \cdot V_{\mathrm{CO}_{2}}^{\prime} / P_{\mathrm{aCO}_{2}} \cdot\left(1-V_{\mathrm{D}} / V_{\mathrm{T}}\right)
$$

which, when viewed at level of the alveolar gas-exchange process, simplifies to:

$$
V_{\mathrm{A}}^{\prime}=863 \cdot V_{\mathrm{CO}_{2}}^{\prime} / P_{\mathrm{aCO}_{2}}
$$

where $V_{\mathrm{A}}^{\prime}$ is alveolar ventilation.

Over a wide work-rate range, expressing $V_{\mathrm{E}}^{\prime}$ as a function of $V_{\mathrm{CO}_{2}}^{\prime}$ normally results in a linear relationship (figure 1a):

$$
V_{\mathrm{E}}^{\prime}=m \cdot V_{\mathrm{CO}_{2}}^{\prime}+c
$$

where $m$ is the slope (i.e. $\Delta V_{\mathrm{E}}^{\prime} / \Delta V^{\prime} \mathrm{CO}_{2}$, normally $\sim 25$ when reported in the same units, e.g. $\mathrm{L} \cdot \mathrm{min}^{-1}$, $\mathrm{mL} \cdot \mathrm{min}^{-1}$ etc., with $V_{\mathrm{E}}^{\prime}$ being reported as body temperature and pressure, saturated and $V_{\mathrm{CO}_{2}}^{\prime}$ as standard temperature and pressure, dry), and $c$ is the $V_{\mathrm{E}}^{\prime}$ intercept (normally $\sim 3-5 \mathrm{~L} \cdot \mathrm{min}^{-1}$ ) when allowance is made for breathing apparatus (valve or facemask) dead space [17-19], i.e. by subtracting the product of apparatus $V_{\mathrm{D}}$ and breathing frequency from the measured $V_{\mathrm{E}}^{\prime}$. Without this correction, the $V_{\mathrm{E}}^{\prime}$ intercept will be over-estimated, to a degree that naturally depends on the size of the apparatus $V_{\mathrm{D}}$.

Encapsulated in $m$ are the composite response profiles of $P_{\mathrm{aCO}}$ and $V_{\mathrm{D}} / V_{\mathrm{T}}$, while $c$ is the value of $V_{\mathrm{E}}^{\prime}$ at a hypothetical $V_{\mathrm{CO}_{2}}^{\prime}$ of zero. And as the $V_{\mathrm{A}}^{\prime}-V^{\prime} \mathrm{CO}_{2}$ relationship is normally also linear but intersects the origin (i.e. no $V_{\mathrm{A}}^{\prime}$ intercept) [20], the corresponding relationship between dead space ventilation $\left(V^{\prime}{ }_{\mathrm{D}}\right)$ and $V^{\prime} \mathrm{CO}_{2}$ has also to be linear, with a $V^{\prime}{ }_{\mathrm{D}}$ intercept equal to $c$.

For the rapidly changing work-rate protocols used in CPET, the range of $V_{\mathrm{E}}^{\prime}-V_{\mathrm{CO}_{2}}^{\prime}$ linearity actually extends beyond LT. That is, the onset of respiratory compensation for the metabolic acidosis (the 

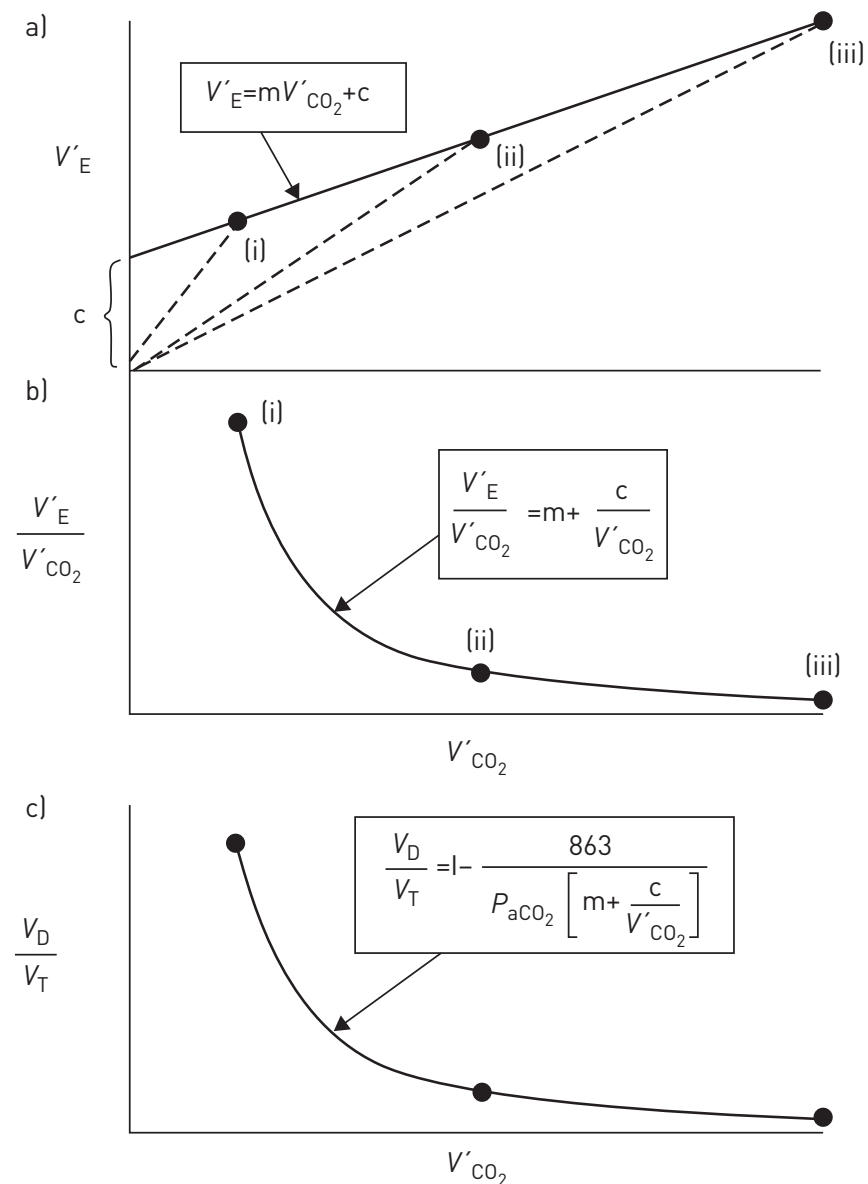

FIGURE 1 Schematic representation of a) ventilation $\left(V_{E}^{\prime}\right)$, b) ventilatory equivalent for $\mathrm{CO}_{2}\left(V_{E}^{\prime} / V_{\mathrm{CO}_{2}}^{\prime}\right)$ and c) physiological dead space fraction of the breath $\left(V_{\mathrm{D}} / V_{\mathrm{T}}\right)$ as a function of $\mathrm{CO}_{2}$ output $\left(V^{\prime} \mathrm{CO}_{2}\right)$ during rapid-incremental (or ramp) exercise for work rates where arterial $\mathrm{CO}_{2}$ tension $\left(P_{\mathrm{acO}}\right)$ is assumed to be stable. $m: V_{E}^{\prime}-V^{\prime}{ }_{C_{2}}$ slope; $c: V_{E}^{\prime}$ intercept. Modified with permission from a, b) [15] and c) [16].

respiratory compensation point (RCP)) is delayed relative to the onset of the acidosis itself, i.e. at LT (figure 2) $[7,8,14,21-24]$. As a result, $V_{\mathrm{E}}^{\prime}$ continues to remain coupled to $V_{\mathrm{CO}_{2}}^{\prime}$, providing a supra-threshold region of $P_{\mathrm{aCO}}$ stability (termed "isocapnic buffering", in a physiological rather than a physicochemical sense) [25]. In contrast, for slow-incremental and steady-state exercise tests, LT and the RCP are coincident. The slow response dynamics of the compensatory hyperventilation, in the context of rapid work-rate incrementation rates, has been suggested to reflect the carotid body chemoreceptors having an amplitude or time-related threshold for metabolic $\mathrm{H}^{+}$detection [8], possibly expressed through slow intracellular expression of the metabolic acidosis and/or slow subsequent signal transduction at $\mathrm{H}^{+}$-sensitive type I TASK-1 potassium channels [26, 27]. The RCP is thus a manifestation of $\mathrm{H}^{+}$-related ventilatory control (and is therefore not a metabolic construct). For example, the RCP becomes closer to LT when carotid chemoreflex drive is enhanced by the imposition of hypoxia [28-30] but farther from LT when the work rate is incremented more rapidly [29-31].

The $V^{\prime}{ }_{\mathrm{E}} / V^{\prime}{ }_{\mathrm{CO}}$, response

$V_{\mathrm{E}}^{\prime} / V_{\mathrm{CO}_{2}}^{\prime}$ can be viewed as a variable "derived” from the $V_{\mathrm{E}}^{\prime}-V_{\mathrm{CO}_{2}}^{\prime}$ relationship; being numerically equal to the slope of a hypothetical line joining a given $V_{\mathrm{E}}^{\prime}, V^{\prime} \mathrm{CO}_{2}$ point to the origin (dashed lines in figure 1a). The linearity of the $V_{\mathrm{E}}^{\prime}-V_{\mathrm{CO}_{2}}^{\prime}$ relationship and its positive $V_{\mathrm{E}}^{\prime}$ intercept (figure 1a; equation 5) requires $V^{\prime}{ }_{E} / V^{\prime} \mathrm{CO}_{2}$ to decline hyperbolically as work rate and therefore $V_{\mathrm{CO}_{2}}$ increase (figure $1 \mathrm{~b}$ ). Over a considerable portion of the tolerable work-rate range, $V^{\prime}{ }_{E} / V^{\prime}{ }_{\mathrm{CO}_{2}}$ clearly exceeds the $V^{\prime}{ }_{\mathrm{E}}-V^{\prime} \mathrm{CO}_{2}$ slope $(m)$, specifically by the variable factor $c / V^{\prime} \mathrm{CO}_{2}$ :

$$
V_{\mathrm{E}}^{\prime} / V_{\mathrm{CO}_{2}}^{\prime}=m+c / V_{\mathrm{CO}_{2}}^{\prime}
$$




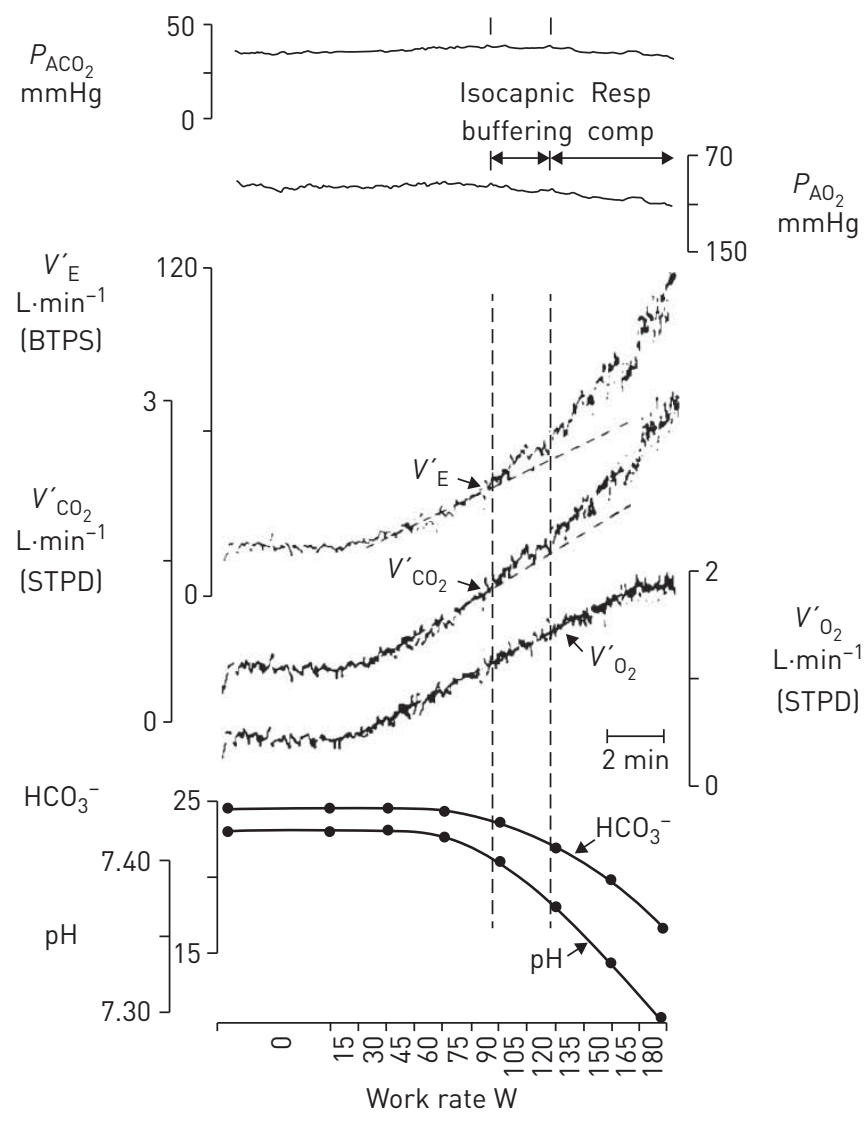

FIGURE 2 Alveolar end-tidal $P_{\mathrm{CO}_{2}}$ and $P_{\mathrm{O}_{2}}\left(P_{\mathrm{ACO}_{2}}, P_{\mathrm{AO}_{2}}\right)$, ventilation $\left(V_{\mathrm{E}}^{\prime}\right), \mathrm{CO}_{2}$ output $\left(V_{\mathrm{CO}_{2}}^{\prime}\right), \mathrm{O}_{2}$ uptake $\left(V_{\mathrm{O}_{2}}^{\prime}\right)$, arterial $\left[\mathrm{HCO}_{3}^{-}\right]$and arterial $\mathrm{pH}$ as a function of work rate for a rapid-incremental cycle-ergometer exercise test. The lactate threshold occurs when arterial $\left[\mathrm{HCO}_{3}^{-}\right]$starts to buffer the metabolic acidosis, evidenced in the accelerating $V^{\prime} \mathrm{CO}_{2}$ response (left vertical dashed line). As $V_{E}^{\prime}$ conti-nues to respond in proportion to $V^{\prime} \mathrm{CO}_{2}$, it therefore increases out of proportion to $V^{\prime} \mathrm{O}_{2}$, and $P_{\mathrm{AO}}$ there-fore begins to rise. $P_{\mathrm{ACO}}$ remains stable until respiratory compen-sation for the metabolic acidosis develops (right vertical dashed line; isocapnic buffering). Beyond this point, $V^{\prime}{ }_{\mathrm{E}}$ increases at a greater rate than $V^{\prime} \mathrm{CO}_{2}$, and $P_{\mathrm{ACO}_{2}}$ therefore starts to decreases (respiratory compensation). Reproduced with permission from [3].

As $c / V^{\prime} \mathrm{CO}_{2}$ diminishes with increasing work rate (and $V^{\prime} \mathrm{CO}_{2}$ ), $V^{\prime}{ }_{\mathrm{E}} / V^{\prime} \mathrm{CO}_{2}$ will decline to achieve an asymptotic value at high levels of $V_{\mathrm{CO}_{2}}^{\prime}$ that is equal to $m$ (figure $1 \mathrm{~b}$ ) $[15,17,32]$.

"It is important, therefore, that if the values of the ventilatory equivalent for $\mathrm{CO}_{2}$ are to be used for characterising a subject's ventilatory response to exercise they should be reported together with the values of $V^{\prime} \mathrm{CO}_{2}$ at which they were obtained. Or, better still, both the slope and intercept parameters of the $V_{\mathrm{E}}^{\prime}-V^{\prime} \mathrm{CO}_{2}$ relationship should be defined" [15]. And it should also be noted that $V^{\prime}{ }_{E} / V^{\prime} \mathrm{CO}_{2}$ will equal $m$ not only at very high $V_{\mathrm{CO}_{2}}^{\prime}$ values, but also when the $V^{\prime}{ }_{\mathrm{E}} / V^{\prime} \mathrm{CO}_{2}$ relationship extrapolates to the origin (i.e. when $c=0$ ) (equation 6) [18, 19].

Equation 1 indicates that maintained regulation of $P_{\mathrm{aCO}}$ requires the response profiles of $V_{\mathrm{E}}^{\prime} / V^{\prime} \mathrm{CO}_{2}$ and $V_{\mathrm{D}} / V_{\mathrm{T}}$ to be qualitatively and quantitatively matched. That is, the normal hyperbolic decline of $V_{\mathrm{E}}^{\prime} / V^{\prime} \mathrm{CO}_{2}$ with increasing work rate (figure $1 \mathrm{~b}$ ) necessitates a similar profile of $V_{\mathrm{D}} / V_{\mathrm{T}}$ decline (figure 1c) [10, 15, 29]:

$$
V_{\mathrm{D}} / V_{\mathrm{T}}=1-\left(863 /\left(P_{\mathrm{aCO}_{2}} \cdot\left(m+c / V_{\mathrm{CO}_{2}}^{\prime}\right)\right)\right)
$$

Substituting $V_{E}^{\prime} / V^{\prime} \mathrm{CO}_{2}$ for $m+c / V^{\prime} \mathrm{CO}_{2}$ from equation 6 into equation 7 , and re-arranging in terms of $V^{\prime}{ }_{\mathrm{E}} / V^{\prime} \mathrm{CO}_{2}$, yields: 


$$
V_{\mathrm{E}}^{\prime} / V_{\mathrm{CO}_{2}}^{\prime}=863 /\left(P_{\mathrm{aCO}_{2}} \cdot\left(1-V_{\mathrm{D}} / V_{\mathrm{T}}\right)\right)
$$

A modest contribution to the declining $V_{\mathrm{D}} / V_{\mathrm{T}}$ with increasing work rate derives from a more-even perfusion of the lungs $\left(Q^{\prime}\right)$ that results in an improved $V^{\prime}{ }_{\mathrm{A}} / Q^{\prime}$ distribution [33-36]. However, the predominant influence is the consequence of disproportionate increases in $V_{\mathrm{D}}$ and $V_{\mathrm{T}}$; the former being less than the latter. This reflects the compliance of the conducting airways being appreciably less than that of the alveoli.

As for the $V_{\mathrm{E}}^{\prime}-V^{\prime} \mathrm{CO}_{2}$ relationship, the resulting $V_{\mathrm{D}}-V_{\mathrm{T}}$ relationship is normally also linear with a positive $V_{\mathrm{D}}$ intercept [34] which confers hyperbolicity on the $V_{\mathrm{D}} / V_{\mathrm{T}}$ decline. Were $V_{\mathrm{D}} / V_{\mathrm{T}}$ not to decline hyperbolically, a necessary consequence would be the introduction of nonlinearities into the $V_{\mathrm{E}}^{\prime}-V^{\prime} \mathrm{CO}_{2}$ relationship or $P_{\mathrm{aCO}_{2}}$ not being regulated, or both [15], unless, of course, the $V^{\prime} \mathrm{E}$ intercept were to be zero (equations 7 and 8). In this latter situation, therefore, $V_{\mathrm{D}} / V_{\mathrm{T}}$ will not decline with increasing work rate and, if $P_{\mathrm{aCO}_{2}}$ remains regulated, neither will $V_{\mathrm{E}}^{\prime} / V^{\prime} \mathrm{CO}_{2}$.

Exactly how such apparent matching between $V^{\prime}{ }_{\mathrm{E}} / V^{\prime} \mathrm{CO}_{2}$ and $V_{\mathrm{D}} / V_{\mathrm{T}}$ might be mediated has yet to be resolved, but "the system seems to "know" that when $V_{\mathrm{D}} / V_{\mathrm{T}}$ is reduced (making $V_{\mathrm{E}}^{\prime}$ more efficient with respect to $V_{\mathrm{A}}^{\prime}$ ) $V_{\mathrm{E}}^{\prime}$ "needs" to increase less per unit $V_{\mathrm{CO}_{2}}^{\prime}$ to effect its regulatory function, with the necessary logical assumption, of course, that there is such regulation. But unless one is badly confusing subsequence and consequence, it is hard to believe, in the light of the evidence cited above, that there is not." [10].

Ventilatory efficiency indices

The $V_{\mathrm{E}}^{\prime}-V_{\mathrm{CO}_{2}}^{\prime}$ and $V_{\mathrm{E}}^{\prime} / V_{\mathrm{CO}_{2}}^{\prime}$ response profiles provide indices of ventilatory efficiency [1-3] as, respectively, a) the slope of the linear region of the $V^{\prime}{ }^{-} V^{\prime} \mathrm{CO}_{2}$ relationship (i.e. normally up to the RCP) (figure $1 \mathrm{a}$ and b) either $V_{\mathrm{E}}^{\prime} / V^{\prime} \mathrm{CO}_{2}$ at $\hat{\mathrm{LT}}\left(V_{\mathrm{E}}^{\prime} / V_{\mathrm{CO}_{2}}^{\prime} \hat{\mathrm{LT}}\right)$ or its minimum value $\left(V_{\mathrm{E}}^{\prime} / V^{\prime} \mathrm{CO}_{2} \mathrm{~min}\right)$ typically occurring soon thereafter LT but before the RCP (figure 1b), and have been shown to be essentially indistinguishable in healthy individuals [19]. When these several indices are increased relative to normal, ventilatory efficiency is assumed to have decreased (i.e. greater ventilatory inefficiency).

As $V_{\mathrm{E}}^{\prime} / V^{\prime} \mathrm{CO}_{2}$ min approximates the $V_{\mathrm{E}}^{\prime}-V^{\prime} \mathrm{CO}_{2}$ slope at very high $V_{\mathrm{CO}_{2}}^{\prime}$ values (figure $1 \mathrm{a}$ and b) [10, 15,32 , these two indices are essentially equal in fit individuals for whom LT and the RCP occur at relatively high absolute values of $V^{\prime} \mathrm{CO}_{2}$ [19, 37]. Interestingly, slightly higher values for ventilatory efficiency have been reported with ageing [19], and also in females compared to males [19, 37]. Ventilatory efficiency indices have been reported by some to be unaffected by exercise modality (i.e. cycle ergometer versus treadmill) [19], although others report slightly higher values for treadmill exercise in females [38] and in males [39]. Finally, there is some question as to whether test-retest reliability differs between ventilatory efficiency indices, being reported either to be greater for $V^{\prime}{ }_{E} / V^{\prime}{ }_{\mathrm{CO}_{2}} \min$ than for the $V_{\mathrm{E}}^{\prime} / V_{\mathrm{CO}_{2}}^{\prime}$ slope [19] or not to differ [37].

Interpretation of abnormally high values for ventilatory efficiency does require some care, however, recognising that this could reflect impairments in $V_{\mathrm{D}} / V_{\mathrm{T}}$ or $P_{\mathrm{aCO}}$ regulation, or both. For example, higher-then-normal values of $V^{\prime}{ }_{\mathrm{E}}-V^{\prime} \mathrm{CO}_{2}$ slope and $V_{\mathrm{E}}^{\prime} / V^{\prime} \mathrm{CO}_{2}$ min could reflect a low $P_{\mathrm{aCO}_{2}}$ (reflective of a high ventilatory control "gain", as with hyperventilatory conditions such as arterial hypoxaemia, metabolic acidaemia and increased central neural respiratory drive), a high $V_{\mathrm{D}} / V_{\mathrm{T}}$ (reflective of increased $V^{\prime}{ }_{\mathrm{A}} / Q^{\prime}$ mismatch, as in the healthy elderly and lung and cardiovascular disease patients) or both. In addition, a high $V_{\mathrm{E}}^{\prime} / V^{\prime} \mathrm{CO}_{2}$ min might be expected in individuals having a low respiratory quotient (i.e. with a lower-than-normal $\mathrm{CO}_{2}$ production at a given work rate) and, as discussed later, in those having significantly compromised exercise tolerance.

\section{Complicating issues}

\section{$V_{E}^{\prime}-V_{\mathrm{CO}_{2}}^{\prime}$ slope estimation}

From a physiological perspective, it is important that the $V_{\mathrm{E}}^{\prime}-V_{\mathrm{CO}_{2}}^{\prime}$ slope estimate is constrained to the linear region of the relationship, i.e. not beyond the RCP where respiratory compensation for the metabolic acidosis introduces nonlinearity. Thus, while a $V_{\mathrm{E}}^{\prime}-V_{\mathrm{CO}_{2}}^{\prime}$ slope estimate obtained from the entire work-rate range (e.g. [40-42]) tends to be favoured for cardiological cohorts because of demonstrably better prognostication (e.g. [43-46]), the departure from $V_{\mathrm{E}}^{\prime}-V_{\mathrm{CO}_{2}}^{\prime}$ linearity will result in the $V_{\mathrm{E}}^{\prime}-V_{\mathrm{CO}_{2}}^{\prime}$ slope being over-estimated and the $V_{\mathrm{E}}^{\prime}$ intercept being under-estimated, with implications for ventilatory efficiency judgements [47]. 


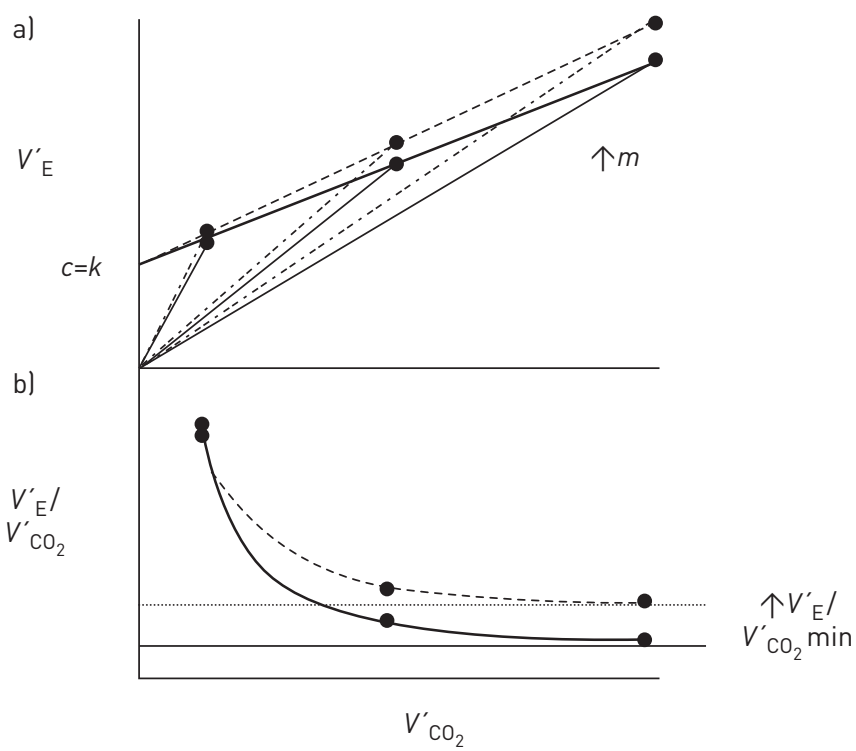

FIGURE 3 Schematic representation of a) the effects of a hypothetical intervention that increased the $V^{\prime}-V^{\prime} \mathrm{CO}_{2}$ slope $(m)$ with no change in the $V_{E}^{\prime}$ intercept $(c)$ on ventilation $\left(V_{E}^{\prime}\right)$ and b) ventilatory equivalent for $\mathrm{CO}_{2}\left(V_{\mathrm{E}}^{\prime} / V^{\prime} \mathrm{CO}_{2}\right)$ as a function of $\mathrm{CO}_{2}$ output $\left(\mathrm{V}^{\prime} \mathrm{CO}_{2}\right)$ during rapid-incremental (or ramp) exercise for work rates where arterial $\mathrm{CO}_{2}$ tension $\left(P_{\mathrm{acO}}\right)$ is assumed to be stable. Solid profiles: pre-intervention; dashed profiles, post-intervention.

Equality between $\mathrm{V}_{E}^{\prime} \mathrm{N}_{\mathrm{CO}_{2}}$ min and $\mathrm{V}_{E^{\prime}}-\mathrm{V}_{\mathrm{CO}_{2}}$ slope

This equality reflects $V^{\prime}{ }_{\mathrm{E}} / V^{\prime} \mathrm{CO}_{2}$ min approximating the $V_{\mathrm{E}}^{\prime}-V_{\mathrm{CO}_{2}}^{\prime}$ slope at high $V_{\mathrm{CO}_{2}}^{\prime}$ values (figure $1 \mathrm{a}$ and b) [10, 15, 32]. However, when circumstances change, maintained equality depends critically on the behaviour of the $V_{\mathrm{E}}^{\prime}$ intercept. For example, were the $V_{\mathrm{E}}^{\prime}-V^{\prime} \mathrm{CO}_{2}$ slope to be caused to increase but with no change in the $V_{\mathrm{E}}^{\prime}$ intercept, this would result in predictable increases in $V_{\mathrm{E}}^{\prime} / V^{\prime} \mathrm{CO}_{2}$ (equation 6) such that the $V^{\prime}{ }_{E} / V^{\prime} \mathrm{CO}_{2}$ response profile would be shifted upwards with a new increased $V^{\prime}{ }_{\mathrm{E}} / V^{\prime} \mathrm{CO}_{2}$ min equal to the new increased $V^{\prime}{ }_{\mathrm{E}}-V^{\prime} \mathrm{CO}_{2}$ slope (figure 3). In contrast, were the $V_{\mathrm{E}}^{\prime}$ intercept to increase but with no change in the $V_{\mathrm{E}}^{\prime}-V_{\mathrm{CO}_{2}}^{\prime}$ slope, the $V_{\mathrm{E}}^{\prime} / V^{\prime} \mathrm{CO}_{2}$-response profile would be shifted upwards with a new increased $V^{\prime}{ }_{\mathrm{E}} / V^{\prime} \mathrm{CO}_{2}$ min that would exceed the unchanged $V^{\prime}{ }_{\mathrm{E}}-V^{\prime} \mathrm{CO}_{2}$ slope (figure 4).

However, when exercise tolerance is severely compromised, the normal equality between $V_{\mathrm{E}}^{\prime} / V^{\prime} \mathrm{CO}_{2}$ min and the $V_{\mathrm{E}}^{\prime}-V_{\mathrm{CO}_{2}}^{\prime}$ slope may not obtain. Thus, in poorly fit individuals and in significantly limited patients, the RCP may be sufficiently low as to occur on the still-falling $V_{\mathrm{E}}^{\prime} / V^{\prime} \mathrm{CO}_{2}$ trajectory [18, 48]. In such a situation, as $V_{E}^{\prime} / V^{\prime} \mathrm{CO}_{2}$ min will exceed the $V^{\prime}{ }_{\mathrm{E}}-V^{\prime} \mathrm{CO}_{2}$ slope, the latter would therefore be the only physiologically meaningful index of ventilatory efficiency. This scenario also has implications for RCP estimation. That is, respiratory compensation could be achieved with $V_{E}^{\prime} / V^{\prime} \mathrm{CO}_{2}$ still declining, but at a lesser rate than isocapnia would require, i.e. decreasing less than $V_{\mathrm{D}} / V_{\mathrm{T}}[29,30]$.

\section{The $\mathrm{V}_{E}^{\prime}$ intercept}

The potential value of incorporating the $V_{\mathrm{E}}^{\prime}$ intercept, conjointly with the $V_{\mathrm{E}}^{\prime}-V_{\mathrm{CO}_{2}}^{\prime}$ slope, into clinical analyses of exercise intolerance in the context of co-morbidities and prognostication is becoming recognised [18, 49-52]. The physiological basis of the $V_{E}^{\prime}$ intercept can only be conjectured on, however. Simply put, it expresses a notional $V^{\prime}{ }_{\mathrm{D}}$ at a hypothetical $V^{\prime} \mathrm{CO}_{2}$ of zero, and therefore is unlikely to represent any actual $V_{\mathrm{D}}^{\prime}[15,17]$ c.f. [51, 53]. In a geometrical sense, the position of the $V_{\mathrm{E}}^{\prime}-V^{\prime} \mathrm{CO}_{2}$ relationship could be considered to be dictated by the resting $V_{\mathrm{E}}^{\prime}, V^{\prime} \mathrm{CO}_{2}$ "operator", such that the $V_{\mathrm{E}}^{\prime}$ intercept is merely a "passive" consequence of the underlying exercise ventilatory control process. Alternatively, the $V_{\mathrm{E}}^{\prime}$ intercept could reflect some mechanistic interplay between $V_{\mathrm{D}} / V_{\mathrm{T}}$ and $P_{\mathrm{aCO}}$ in setting the required exercise $V_{E}^{\prime}[10,54]$. This clearly demands resolution.

$\mathrm{P}_{a \mathrm{CO}_{2}}$ in rapid-incremental exercise

The implicit assumption of a stable $P_{\mathrm{aCO}}$ over a wide range of work rates, accomplished through the proportional hyperbolic behaviours of $V^{\prime}{ }_{\mathrm{E}} / V^{\prime} \mathrm{CO}_{2}$ and $V_{\mathrm{D}} / V_{\mathrm{T}}$ is open to some question for rapid-incremental exercise. That is, while $V_{E}^{\prime}$ evidences a close dynamic coupling to $V_{\mathrm{CO}_{2}}^{\prime}$, its slightly longer time constant 


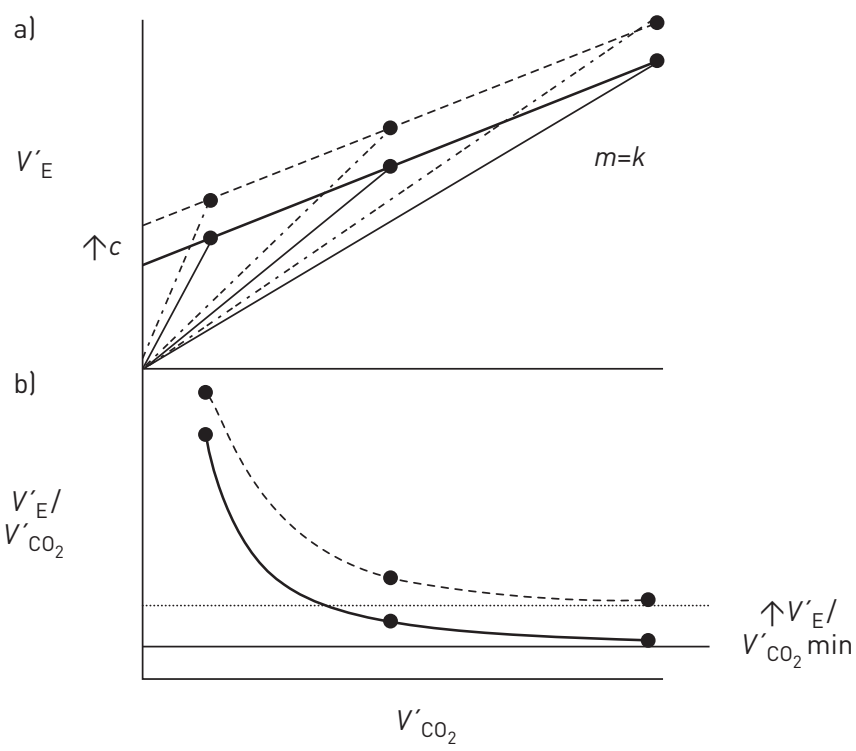

FIGURE 4 Schematic representation of a) the effects of a hypothetical intervention that increased the $V^{\prime} E$-intercept $(c)$ with no change in the $V^{\prime}{ }^{-}-V^{\prime}{ }_{\mathrm{CO}_{2}}$ slope $(m)$ on ventilation $\left(V_{\mathrm{E}}^{\prime}\right)$ and b) ventilatory equivalent for $\mathrm{CO}_{2}\left(V_{\mathrm{E}}^{\prime} / V^{\prime} \mathrm{CO}_{2}\right)$ as a function of $\mathrm{CO}_{2}$ output $\left(V^{\prime} \mathrm{CO}_{2}\right)$ during rapid-incremental or ramp exercise for work rates where arterial $\mathrm{CO} 2$ tension $\left(\mathrm{PacO}_{2}\right)$ is assumed to be stable. Solid profiles: pre-inter-vention; dashed profiles, post-ntervention.

of response [7-9] predicts a modest but systematic increase in $P_{\mathrm{aCO}_{2}}[25,55,56]$. This predictably impacts on ventilatory efficiency estimates, as illustrated by inserting the group-mean gas-exchange responses for ramp exercise reported by Sun et al. [56] into equation 7, with reasonable assumptions being made for the concomitant $V_{\mathrm{D}} / V_{\mathrm{T}}$ responses [33-36]. When the measured $P_{\mathrm{aCO}_{2}}$ values (i.e. increasing from $40.8 \mathrm{mmHg}$ at rest to $44.6 \mathrm{mmHg}$ just prior to the RCP) were used, the $V^{\prime}{ }_{\mathrm{E}}-V^{\prime} \mathrm{CO}_{2}$ slope and $V_{\mathrm{E}}^{\prime}$ intercept were estimated to be 20.0 and $3.92 \mathrm{~L} \cdot \mathrm{min}^{-1}$, respectively (figure 5 , dashed line). This contrasts with slope and intercept values of 22.4 and $2.70 \mathrm{~L} \cdot \mathrm{min}^{-1}$ if $P_{\mathrm{aCO}}$ were constrained to remain at the resting value of $40.8 \mathrm{mmHg}$ (normocapnia) up to the RCP (figure 5, solid line). Likewise, the normocapnic $V_{\mathrm{E}}^{\prime} / V^{\prime} \mathrm{CO}_{2}$

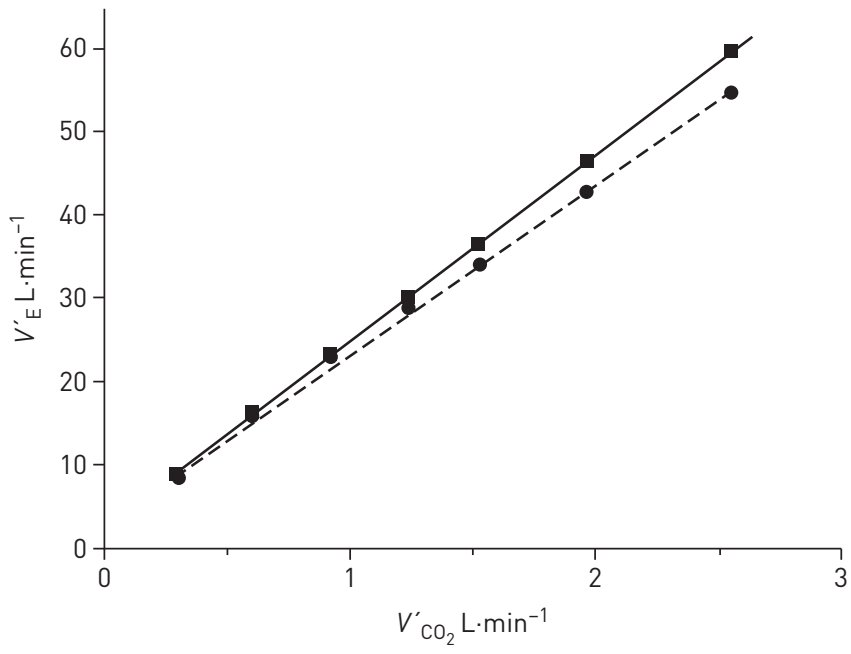

FIGURE 5 The $V^{\prime}{ }^{\prime}-V^{\prime} \mathrm{CO}_{2}$ relationship for ramp exercise in which arterial $\mathrm{CO}_{2}$ tension $\left(P_{\mathrm{acO}}\right)$ has been demonstrated to increase progressively up to the lactate threshold $[25,56,57]$ (dashed line), compared with that obtaining with $P_{\mathrm{acO}_{2}}$ constrained not to increase (solid line). Note the decreased slope in the former condition. Data taken from [56]. 


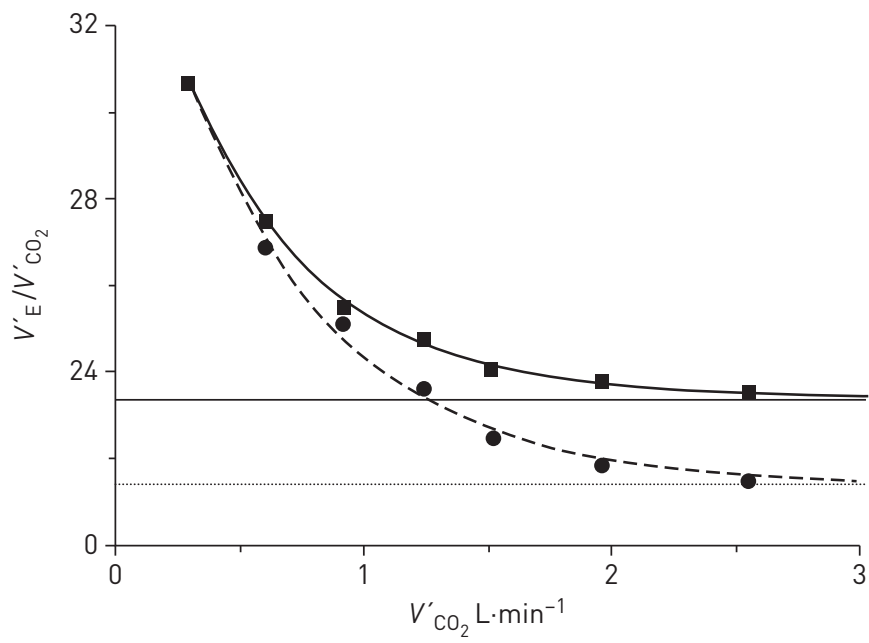

FIGURE 6 The corresponding $V_{E}^{\prime} / V_{\mathrm{CO}_{2}}^{\prime}$ relationships related to figure 5 . Note the depressed $V_{\mathrm{E}}^{\prime} / V^{\prime} \mathrm{CO}_{2}$ profile consequent to the progressive $P_{\mathrm{acO}}$ increase (circles, dashed curve), compared with that obtaining with arterial $\mathrm{CO}_{2}$ tension $\left(P_{\mathrm{acO}}\right)$ constrained not to increase (squares, solid curve). As a result, $V_{E}^{\prime} / V_{\mathrm{CO}_{2}}^{\prime}$ min was decreased in the former condition.

response profile was shifted upwards (figure 6, solid curve) relative to the actual $V^{\prime}{ }_{\mathrm{E}} / V^{\prime} \mathrm{CO}_{2}$ profile (figure 6, dashed curve), with $V_{\mathrm{E}}^{\prime} / V^{\prime} \mathrm{CO}_{2}$ min being 23.5 compared with 21.5. While these differences are numerically modest, this raises the issue of ventilatory inefficiency being underestimated for the standard CPET ramp exercise testing paradigm, if $P_{\mathrm{aCO}}$ regulation is assumed.

Interestingly, the profile of increasing $P_{\mathrm{aCO}}$ with ramp exercise only occurs up to LT. Beyond $\hat{\mathrm{LT}}, P_{\mathrm{aCO}}$ stabilises up to the RCP (i.e. isocapnic buffering) [25, 56]. Paraphrasing Whipp and colleagues "Consequently, $P_{\mathrm{aCO}_{2}}$ becomes constant at [LTT] because of a particular ventilatory response; it does not remain constant because of the lack of one" and "isocapnic buffering during rapid-incremental exercise actually reflects a ventilatory response to the metabolic acidosis which levels a systematically-rising phase of $P_{\mathrm{ETCO}_{2}}$ [end-tidal $\mathrm{CO}_{2}$ tension] and $P_{\mathrm{aCO}_{2}}$ " [25]. While isocapnic buffering does not represent respiratory compensation in the conventional sense (i.e. a $V_{\mathrm{E}}^{\prime}$ response sufficient to elicit a decrease in $P_{\mathrm{aCO}_{2}}$ ), one could reasonably argue that the lack of a continuing increase $P_{\mathrm{aCO}}$ in beyond LT (i.e. a lower-than-expected $P_{\mathrm{aCO}}$ ) does not rule it out.

\section{Conclusions}

What, therefore, does (and does not) a decrease in ventilatory efficiency connote? One is reminded of Moritz Schlick's statement in 1936 that “The meaning of a proposition is the method of its verification" and which he appropriately attributed to Ludwig Wittgenstein [57]. Generically speaking, ventilatory efficiency is simply the $V_{\mathrm{E}}^{\prime}$ "tasked with" clearing metabolically-produced $\mathrm{CO}_{2}$ during exercise, being expressed mathematically as either the $V^{\prime}{ }_{E}-V^{\prime}{ }_{\mathrm{CO}_{2}}$ slope or the value of $V^{\prime}{ }_{\mathrm{E}} / V_{\mathrm{CO}_{2}}^{\prime}$ at LT or just prior to the RCP. However, interpretation of ventilatory efficiency should be undertaken with caution, as high values of $V_{\mathrm{E}}^{\prime}-V^{\prime} \mathrm{CO}_{2}$ slope and $V_{\mathrm{E}}^{\prime} / V^{\prime} \mathrm{CO}_{2}$ min could reflect a low $P_{\mathrm{aCO}_{2}}$, a high $V_{\mathrm{D}} / V_{\mathrm{T}}$ or both; rigorous discrimination therefore requiring simultaneous $P_{\mathrm{aCO}}$ monitoring.

A clear distinction should be drawn between ventilatory efficiency and pulmonary $\mathrm{CO}_{2}$ exchange efficiency; the latter being conventionally quantified as $\left(1-V_{\mathrm{D}} / V_{\mathrm{T}}\right)$ [1-3]. Thus, a decrease in $\left(1-V_{\mathrm{D}} / V_{\mathrm{T}}\right)$ reflects a reduction in gas-exchange efficiency, consequent to $V_{\mathrm{A}}^{\prime} / Q^{\prime}$ mismatching and/or a right-to-left shunt. In such a situation, if $V_{\mathrm{E}}^{\prime}$ is constrained or limited from increasing, $P_{\mathrm{aCO}}$ will rise (as with severely impaired respiratory mechanics). However, in individuals with normal pulmonary function, a high $V_{\mathrm{D}} / V_{\mathrm{T}}$ can simply result from a tachypnoeic pattern of breathing.

In conclusion, if $P_{\mathrm{aCO}}$ is regulated, a high $V_{\mathrm{E}}^{\prime}-V^{\prime} \mathrm{CO}_{2}$ slope is a useful but not rigorous index of a high $V_{\mathrm{D}} / V_{\mathrm{T}}$, unless account is taken of the $V_{\mathrm{E}}^{\prime}$ intercept as is illustrated in figure 4. In contrast, a high $V_{\mathrm{E}}^{\prime} / V_{\mathrm{CO}_{2}}^{\prime}$ min does provide a rigorous index of a high $V_{\mathrm{D}} / V_{\mathrm{T}}$ (equation 8). For this reason, $V_{\mathrm{E}}^{\prime} / V_{\mathrm{CO}_{2}}^{\prime}$ is better viewed as the primary $\mathrm{CO}_{2}$-linked ventilatory control variable than is the $V_{\mathrm{E}}^{\prime}-V_{\mathrm{CO}_{2}}^{\prime}$ slope [10]. And, of course, ventilatory 
efficiency is necessarily defined over a constrained work-rate range, and thus does not address "efficiency" at high and potentially limiting work rates.

Previous articles in this series: No. 1: Laveneziana P, Di Paolo M, Palange P. The clinical value of cardiopulmonary exercise testing in the modern era. Eur Respir Rev 2021; 30: 200187. No. 2: Agnostoni P, Sciomer S, Palermo P, et al. Minute ventilation/carbon dioxide production in chronic heart failure. Eur Respir Rev 2021; 30: 200141. No. 3: Watson M, Ionescu MF, Sylvester K, et al. Minute ventilation/carbon dioxide production in patients with dysfunctional breathing. Eur Respir Rev 2021; 30: 200182.

Provenance: Commissioned article, peer reviewed.

Acknowledgements: This article is dedicated to my longstanding colleague: the late Brian James Whipp who delivered the Jean-Claude Yernault Lecture on "Determinants of the Ventilatory Response to Exercise in Health and Disease: The "Ventilatory Efficiency" Issue" at the 2010 European Respiratory Society International Congress in Barcelona, and to whom a Symposium "Ventilatory Efficiency during Exercise: A Tribute to Brian J. Whipp" was dedicated at the 2013 European Respiratory Society International Congress in Barcelona.

Conflict of interest: None declared.

\section{References}

$1 \quad$ American Thoracic Society, American College of Chest Physicians. ATS/ACCP Statement on cardiopulmonary exercise testing. Am J Respir Crit Care Med 2003; 167: 211-277.

2 Palange $\mathrm{P}$, Ward SA, Carlsen $\mathrm{K}-\mathrm{H}$, et al. Recommendations on the use of exercise testing in clinical practice. Eur Respir J 2007; 29: 185-209.

3 Sietsema KE, Sue DY, Stringer WW, et al. Wasserman \& Whipp's Principles of Exercise Testing and Interpretation. 6th ed. Philadelphia, Wolters-Kluwer, 2020.

4 Means JH. Dyspnoea. Medicine 1924; 3: 309-416.

5 Douglas CG. Co-ordination of the respiration and circulation with variations in bodily activity. Lancet 1927; 210: 213-218.

6 Forster HV, Haouzi P, Dempsey JA. Control of breathing during exercise. Compr Physiol 2012; 2: 743-777.

7 Wasserman K, Whipp BJ, Casaburi R. Respiratory control during exercise. In: Cherniack NS, Widdicombe JG, eds. Handbook of Physiology, Section 3: The Respiratory System. Bethesda, MD, American Physiological Society, 1986; pp. 595-619.

8 Whipp BJ, Ward SA. The coupling of ventilation to pulmonary gas exchange during exercise. In: Whipp BJ, Wasserman K, eds. Pulmonary Physiology and Pathophysiology of Exercise. New York, Dekker, 1991; pp. 271-307.

9 Wasserman K, Whipp BJ, Casaburi R, et al. $\mathrm{CO}_{2}$ flow to the lungs and ventilatory control. In: Dempsey JA, Reed CE, eds. Muscular Exercise and the Lung. Madison, University of Wisconsin Press, 1977; pp. 105-135.

10 Whipp BJ. Control of the exercise hyperpnea: the unanswered question. Adv Exp Med Biol 2008; 605: 16-21.

11 Sutton JR, Jones NL. Control of pulmonary ventilation during exercise and mediators in the blood: $\mathrm{CO}_{2}$ and hydrogen ion. Med Sci Sports 1979; 11: 198-203.

12 Johnson RL Jr, Heigenhauser GJF, Hsia CCW, et al. Determinants of gas exchange and acid-base balance during exercise. In: Rowell LB, Shepherd JT, eds. Handbook of Physiology, Section 12: Exercise: Regulation and Integration of Multiple Systems. New York, Oxford University Press, 1996; pp. 515-584.

13 Lindinger MI, Heigenhauser GJF. Effects of gas exchange on acid-base balance. Compr Physiol 2012; 2: 2203-2254.

14 Wasserman K, Casaburi R. Acid-base regulation during exercise in humans. In: Whipp BJ, Wasserman K, eds. Pulmonary Physiology and Pathophysiology of Exercise. New York, Dekker, 1991; pp. 405-448.

15 Whipp BJ, Ward SA. Cardiopulmonary coupling during exercise. J Exp Biol 1982; 100: 175-193.

16 Ward SA. Ventilatory control in humans: constraints and limitations. Exp Physiol 2007; 92: 357-366

17 Davis JA, Whipp BJ, Wasserman K. The relation of ventilation to metabolic rate during moderate exercise in man. Eur J Appl Physiol 1980; 44: 97-108.

18 Neder JA, Berton DC, Arbex FF, et al. Physiological and clinical relevance of exercise ventilatory efficiency in COPD. Eur Respir J 2017; 49: 1602036.

19 Sun XG, Hansen JE, Garatachea N, et al. Ventilatory efficiency during exercise in healthy subjects. Am J Respir Crit Care Med 2002; 166: 1443-1448.

20 Jones NL. New tests to assess lung function. Exercise testing in pulmonary evaluation: rationale, methods and the normal respiratory response to exercise. N Engl J Med 1975; 293: 541-544.

21 Rausch SM, Whipp BJ, Wasserman K, et al. Role of the carotid bodies in the respiratory compensation for the metabolic acidosis of exercise in humans. J Physiol (Lond) 1991; 444: 567-578. 
22 Scheuermann BW, Kowalchuk JM. Attenuated respiratory compensation during rapidly incremented ramp exercise. Respir Physiol 1998; 114: 227-238.

23 Ward SA, Whipp BJ. Influence of body $\mathrm{CO}_{2}$ stores on ventilatory-metabolic coupling during exercise. In: Honda $\mathrm{Y}$, Miyamoto Y, Konno K, Widdicombe JG, eds. Control of Breathing and its Modeling Perspective. New York, Plenum Press, 1992; pp. 425-431.

24 Whipp BJ. The control of exercise hyperpnea. In: Hornbein TF, ed. Regulation of Breathing. New York, Marcel Dekker, 1981; pp. 1069-1139.

25 Whipp BJ, Davis JA, Wasserman K. Ventilatory control of the "isocapnic buffering" region in rapidlyincremental exercise. Respir Physiol 1989; 76: 357-368.

26 Buckler KJ, Vaughan-Jones RD, Peers $\mathrm{C}$, et al. Effects of extracellular $\mathrm{pH}, \mathrm{PCO}_{2}$ and $\mathrm{HCO}_{3}^{-}$on intracellular $\mathrm{pH}$ in isolated type-I cells of the neonatal rat carotid body. J Physiol (Lond) 1991; 444: 703-721.

27 Buckler KJ, Williams BA, Honore E. An oxygen, acid and anaesthetic sensitive TASK-like background potassium channel in rat arterial chemoreceptor cells. J Physiol (Lond) 2000; 525 Pt 1: 135-142.

28 Takano N. Respiratory compensation point during incremental exercise as related to hypoxic ventilatory chemosensitivity and lactate increase in man. Jpn J Physiol 2000; 50: 449-455.

29 Ward SA. Determinants of the physiological systems' responses to muscular exercise in healthy subjects. In: Palange P, Laveneziana P, Neder JA, Ward SA, eds. Clinical Exercise Testing (ERS Monograph). Sheffield, European Respiratory Society, 2018; pp. 1-33.

30 Whipp BJ. Physiological mechanisms dissociating pulmonary $\mathrm{CO}_{2}$ and $\mathrm{O}_{2}$ exchange dynamics during exercise. Exp Physiol 2007; 92: 347-355.

31 Leo JA, Sabapathy S, Simmonds MJ, et al. The respiratory compensation point is not a valid surrogate for critical power. Med Sci Sports Exerc 2017; 49: 1452-1460.

32 Whipp BJ. The bioenergetic and gas-exchange basis of exercise testing. Clin Chest Med 1994; 15: 173-192.

33 Jones NL, McHardy GJ, Naimark A, et al. Physiological dead space and alveolar-arterial gas pressure differences during exercise. Clin Sci 1966; 31: 19-29.

34 Lamarra N, Whipp BJ, Ward SA. Physiological inferences from intra-breath measurement of pulmonary gas exchange. Proc Ann Int Conf IEEE/EMBS 1988; pp. 825-826.

35 Wasserman K, VanKessel AL, Burton GG. Interaction of physiological mechanisms during exercise. J Appl Physiol 1967; 22: 71-85.

36 Whipp BJ, Wasserman K. Alveolar-arterial gas tension differences during graded exercise. J Appl Physiol 1969; 27: 361-366.

37 Davis JA, Sorrentino KM, Ninness EM, et al. Test-retest reliability for two indices of ventilatory efficiency measured during cardiopulmonary exercise testing in healthy men and women. Clin Physiol Funct Imaging 2006; 26: 191-196.

38 Davis JA, Tyminski TA, Soriano AC, et al. Exercise test mode dependency for ventilatory efficiency in women but not men. Clin Physiol Funct Imaging 2006; 26: 72-78.

39 Elliott $A D$, Grace F. An examination of exercise mode on ventilatory patterns during incremental exercise. Eur J Appl Physiol 2010; 110: 557-562.

40 Andreas S, Morguet AJ, Werner GS, et al. Ventilatory response to exercise and to carbon dioxide in patients with heart failure. Eur Heart J 1996; 17: 750-755.

41 Buller NP, Poole-Wilson PA. Mechanism of the increased ventilatory response to exercise in patients with chronic heart failure. Br Heart J 1990; 63: 281-283.

42 Davey $\mathrm{P}$, Meyer T, Coats A, et al. Ventilation in chronic heart failure: effects of physical training. $\mathrm{Br}$ Heart $\mathrm{J}$ 1992; 68: 473-477.

43 Ferreira EVM, Ota-Arakaki JS, Ramos RP, et al. Optimizing the evaluation of excess exercise ventilation for prognosis assessment in pulmonary arterial hypertension. Eur J Prev Cardiol 2014; 21: 1409-1419.

44 Ingle L, Goode K, Carroll S, et al. Prognostic value of the $V^{\prime} \mathrm{E}-V^{\prime} \mathrm{CO}_{2}$ slope calculated from different time intervals inpatients with suspected heart failure. Int J Cardiol 2007; 118: 350-355.

45 Myers J, Oliveira R, Dewey F, et al. Validation of a cardiopulmonary exercise test score in heart failure. Circ Heart Fail 2013; 6: 211-218.

46 Tabet JY, Beauvais F, Thabut G, et al. A critical appraisal of the prognostic value of the $V^{\prime} \mathrm{E} / \mathrm{V}^{\prime} \mathrm{CO}_{2}$ slope in chronic heart failure. Eur J Cardiovasc Prev Rehab 2003; 10: 267-272.

47 Ward SA. Commentary on "Mechanism of augmented exercise hyperpnea in chronic heart failure and dead space loading" by Poon and Tin. Respir Physiol Neurobiol 2013; 189: 203-210.

48 Neder JA, Nery LE, Peres C, et al. Reference values for dynamic responses to incremental cycle ergometry in males and females aged 20 to 80. Am J Respir Crit Care Med 2001; 164: 1481-1486.

49 Apostolo $\mathrm{A}$, Laveneziana $\mathrm{P}$, Palange $\mathrm{P}$, et al. Impact of chronic obstructive pulmonary disease on exercise ventilatory efficiency in heart failure. Int J Cardiol 2015; 189: 134-140.

50 Poon C-S, Tin C. Mechanism of augmented exercise hyperpnea in chronic heart failure and dead space loading. Respir Physiol Neurobiol 2013; 186: 114-130. 
51 Teopompi E, Tzani P, Aiello M, et al. Excess ventilation and ventilatory constraints during exercise in patients with chronic obstructive pulmonary disease. Respir Physiol Neurobiol 2014; 197: 9-14.

52 Teopompi E, Tzani P, Aiello M, et al. Ventilatory response to carbon dioxide output in subjects with congestive heart failure and in patients with COPD with comparable exercise capacity. Respir Care 2014; 59: 1034-1041.

53 Agostoni P, Apostolo A, Sciomer S. Evolution of the concept of ventilatory limitation during exercise. Combining the pneumologist and cardiologist point of view. Respir Physiol Neurobiol 2011; 179: 127-128.

54 Ward SA. Exercise physiology: control of the exercise hyperpnea. Curr Opin Physiol 2019; 10: 166-172.

55 Lamarra N, Ward SA, Whipp BJ. Model implications of gas exchange dynamics on blood gases in incremental exercise. J Appl Physiol 1989; 66: 1539-1546.

56 Sun XG, Hansen JE, Stringer WW, et al. Carbon dioxide pressure-concentration relationship in arterial and mixed venous blood during exercise. J Appl Physiol 2001; 90: 1798-1810.

57 Schlick M. Meaning and verification. Philos Rev 1936; 45: 339-369. 